\title{
Reviewing Teacher Evaluation of Rewards and Punishments: The Overview of Chinese Teacher Evaluation Research
}

\author{
Wang Jiayi and Cheng Ling \\ School of Education, Northwest Normal University, Gansu, Lanzhou 730070, China \\ Correspondence should be addressed to Wang Jiayi, wangjy@nwnu.edu.cn \\ Received 17 September 2012; Accepted 24 October 2012 \\ Academic Editor: Hoi Yan Cheung
}

Copyright () 2012 W. Jiayi and C. Ling. This is an open access article distributed under the Creative Commons Attribution License, which permits unrestricted use, distribution, and reproduction in any medium, provided the original work is properly cited.

The authors chose the teacher evaluation pieces literature of Chinese academic studies as the research object, analyzed the domestic dynamic and the views of some experts in this field, and summarized and compiled the research approaches and research methods of the UK and USA. The study found that whether at China or abroad, the study route is basically along the reward and punishment evaluation, from developmental evaluation to the performance evaluation, and compared to the foreign study, the Chinese studies, whether in theory or in practice, are relatively backward. Combined with the domestic situation, this study proposes a number of constructive suggestions.

\section{The General Situations of Research}

Teacher evaluation is an important way to identify the performance of teachers and improve teacher quality, improving the work of teachers and schools. With the power of pull-driven education reform and teacher professional development theory, and as the Government's efforts to teacher construction increase, combined with social cares and supports of public education, teacher's role is undergoing a positive change in the common effect of the various internal and external forces. Therefore, teacher evaluation has also became one of the hot issues in the current domestic academia and the education sector. This study is based on the CNKI literatures, through information search, arrangement, analysis, and summary, and obtained results are as follows.

The first literature retrieved form CNKI of the explicitly put forward "teacher evaluation" was Teacher Evaluation published in the Journal of Xuchang Teachers College in December 1985 written by Xu Gaohou, while the earliest introduction of foreign ideological experience was American Teacher Evaluation in the Malady written by Huang Zhicheng in March 1986, published in the Foreign Education Information. This study found that 1998 is an important point to jump in. Before 1998, domestic academic research on teacher evaluation was not particularly warm, and the annual amount of literature was about 10-20 articles, among these authors: Zhao Muxi from the Fengtai UNESCO, Chen Xiaoda from East China Normal University, and Wang Yuguang from Fujian Normal University, having more published articles. Since 1998, the academic study of "teacher evaluation" is becoming enthusiastic. In each year, the number of documents in the exponential growth represents the development trend of straight up as shown earlier. Although in the last century teacher evaluation domestic research progress was slow, early in May 1984, China has joined the International Association for Evaluation of Educational Achievement (IEA), and in May 1991, the first educational supervision meeting had promulgated Provisional Regulations of Educational Supervision, and this marked the formal introduction of teacher evaluation of official documents. However, this study found that the impetus for more research on teacher evaluation was led by the international trend of thought, and the role of policy and organization of the national level was a bit weak. The following is a simple introduction and summary of Chinese academic research in this area.

\section{Introducing Two Key Persons}

From Figure 1, it can be clearly seen that since 1998, the changing number of the relevant domestic teacher evaluation 


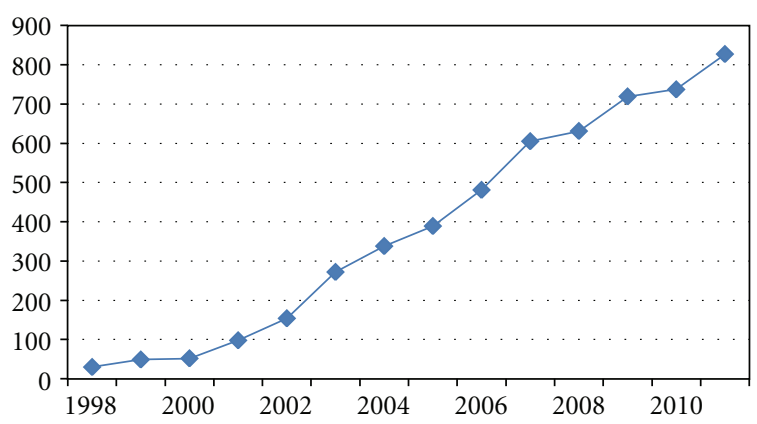

Figure 1: 1998-2011 CNKI related to "teacher evaluation" of the literature quantity change chart.

research articles present a linear rising trend. The number of articles had been changing from 30 in 1998 to 828 in 2011, it increased 27 times. If looking from the curvature of the curve, it can be seen that after 2000 the curvature is significantly greater than before. Analyzed it combined with the domestic education situation, it could be drawn the conclusion: the new round of education reform played an important role. All of the sudden outbreak appear after 1998. In addition to the increase of journals and the strengthening of the research groups outside, one of the most powerful in theory undoubtedly comes from the publication of the classic book The System of Appraisal for Development in 1998, which was written by Wang Binhua at East China Normal University (it is also his Ph.D. thesis). According to incomplete statistics, since then, among all the Chinese academic researches on teacher evaluation, the $1 / 3$ outputs of the literature were affected (especially in 1999-2005, included in the research topic "teacher evaluation," in 372 literatures, there are 126 having the key words "development," "developing teacher evaluation" and "development of teacher evaluation mode," and those references in these works had been affected by his works). It puts forward "developmental teacher evaluation system" and the "teacher evaluation system of rewards and punishments" as two very different purposes of assessment system. The authors proposed their evaluation system from a social, political, economic, cultural perspective and therefore overcome the defect of "teacher evaluation system of rewards and punishments". Although some of these ideas and conclusions cause the academic question and debate, it, in a certain period of historical position of benchmarking, is of no objection. Analyzing all of the 5821 articles (expired on July 1, 2012) about "teacher evaluation," we found that Wang in this field is the most abundant. It can be said that in the long period of time inherent in this field, he has played the important role of navigator. Having early years of visiting fellow experience in the UK, Wang was also one of the earliest scholars to introduce the English teacher evaluation experiences (in 1995, he had published the Teacher Evaluation System and the Major Initiatives of the British Educational Reform in Foreign Educational Material, and before him, only Tu Yong had published British Teachers Evaluation Review in Foreign Educational Material in 1993). Meanwhile, since
2003, he had successively introduced a series of teacher evaluation models about "contract planning act," "principal colleagues assessment," "teaching portfolio," "microteaching evaluation," "elimination system," "performance evaluation method," "value-added assessment method," and so forth, in a number of educational journals [1-6]. In 2005 he had published this new book Teacher Evaluation: Performance Management and Professional Development in the field of teacher evaluation. It can be said that this classic book, in a short period of time, has caused great concerns of the academic studies of other researchers and played a good help.

Because professor Wang became famous earlier, he has been recognized to dominate the field by the academics, but around its accolades in the sky, there also has been a new star on the rise, this is the Beijing Normal University Professor Cai Yonghong. When it came to a new century,a statistical study on the teacher evaluation reveals that the highest citation frequency is Caiyong Hong and Huang Tianyuan published the Origin of the Teacher Evaluation Studies: Problems and Development Trends in the Journal of Beijing Normal University ([7], no. 1, cited 245 times). In addition, in the ranking of "citation frequency," there are three articles in the top 10 about Cai, which are Review of Research on Teacher Performance Assessment and Reflection published in Higher Teacher Education ([8], no. 5, cited 176 times, ranked no. 4), Teacher Performance Evaluation Theory and Practice published in Teacher Education Research ([9], no. 1, cited 121 times, ranked no. 6), and Student Evaluation of Teacher Performance confirmatory factor analysis published in Acta Psychologica Sinica ([10], no. 5, cited 103 times, ranked no. 10). Statistics found that Cai has 9 articles in "teacher evaluation," especially about "teacher performance evaluation," and has the innovative concept of "relationship performance" [9]. In addition, Cai's doctoral thesis Teachers' Job Performance: The Structure and Its Influencing Factors also had won the 2004 National Excellent Doctoral Dissertation. Between 2001 and 2006, Cai had continuously presided over the more important issues of teacher evaluation. For example, in 2001, she had presided over the structure of Beijing Normal University Youth Fund the Teachers' Job Performance and Its Influencing Factors. In 2002, as the second host to participate in teacher evaluation method of the Beijing "10th Five-Year Plan" key project Quality Education; June 2002-June 2005, she had presided over the completion of the Beijing Yucai School cross-cutting project Teacher Evaluation Methods; December 2003-December 2006, and she had presided over the National Education Science "10th Five-Year Plan" key project Growth of Innovative Teachers and Teacher Performance. Although Wang had published the book Teacher Evaluation: Performance Management and Professional Development in 2005, but compared with Cai in "Teacher Performance Evaluation," Wang's article had been published later. In this field, the impact force and research benefits of Cai are larger, and Cai projects were earlier than 2005. So, Cai became another expert in the field of teacher evaluation after Wang. 


\section{Evaluation of Rewards and Punishments, Evaluation of Development, and Performance Evaluation}

The foregoing data have shown that, before 1998, the annual number of literature in China was not much about the evaluation of teachers, Chinese academic research on teacher evaluation was still in the initial stage, and the subject of the study was still stuck on the basic theory. After we have had statistics on "citations," we found the top 3 articles. In addition to Cai's article, the other two are Developing Teacher Evaluation Theories and Models which was published in Educational Theory and Practice ([11], no. 12) and written by Liu Yao, Zhejiang Normal University, (cited 234 times, ranked no. 2) and Overseas Development of the Trend of Development of Teacher Evaluation published in Comparative Education Research ([12], no. 1) and written by Zhao Xibin, Beijing Normal University, (cited 208 times, ranked no. 3). The analysis showed that in addition to Cai's article, the other two are "developing teacher evaluation," pieces of literature. Then, statistical analysis on the key words of the articles found in 1999-2005 period and "developmental evaluation" and "reward and punishment evaluation" of the content closer to the key words had the highest proportion, while after 2005, a substantial surge in the number of articles with the keywords "performance evaluation," could also say that the country of the basic theory on teacher evaluation was basically carried out among these three theories. The following study is to do a brief summary.

3.1. Reward and Punishment Evaluation. Some "reward and punishment evaluation" studies are also known as "traditional evaluation," "normative assessment," "judgment evaluation," "management evaluation," or "summative evaluation," considered to be as a "top-down" evaluation mode. The aim is to approve the effectiveness of teaching, and the purpose is to reward, punish, and sort [13] and focus only on the results of a summative, historical, and utilitarian evaluation. Also evaluation of the screening, with emphasis, plays a supervisory role, through the incentive mechanism for managers to teachers to make the appointment, promotion, demotion, and salary, or increase bonuses and other decision making procedures to provide convincing basis $[14,15]$. This evaluation is considered to be able to mobilize the enthusiasm of the teachers, and to promote the qualities of teachers' groups. This study suggests that this is the understanding of the limitations of both historical time and space constraints, but also not only the limitations of personal thoughts. In the evaluation of the development of the discussion, more researchers had proposed different views.

3.2. The Development of Evaluation. "Developmental evaluation" is to promote the future development of the teachers for the purpose of facing the future, and not only focusing on a formative evaluation of the results of the processoriented, besides,it is also an expectation evaluation and incentive $[14,15]$. It is an evaluation system since the 1980 s originated in the United Kingdom. It does not only focus on the performance of individual teacher, and it pays more attention to the future development of teachers and school development, as in the book The System of Appraisal for Development written by Wang, in which the theory origin was being affected by the influence of British ideas. In the book, he pointed out that the main features of the development of evaluation are (1) school leaders to focus on the future development of the teachers; (2) emphasis on the authenticity and accuracy of teacher evaluation; (3) focus on the teacher's personal values, ethical values; (4) implementation of teacher evaluation among colleagues; (5) to promote the future development of teachers by the evaluators and teachers; (6) to play the enthusiasm of all teachers; (7) to improve the awareness of the participation of all teachers and enthusiasm; (8) to expand the channels of communication; (9) evaluation plan for the development of evaluators and teachers recognized by the evaluation of the two sides shared responsibilities to achieve development goals; (10) focus on long-term goals [16]. The new type of teacher evaluation is to evaluate the advantages and disadvantages of each other for teachers and to provide an opportunity to formulate future development goals for evaluators and evaluation of object, with educational and informational effectiveness [17]. The purposes of the evaluation are the following: (1) to promote the professional development of teachers; (2) to advocate the teachers of individualized teaching; (3) to stressed on teachers' own teaching behavior analysis and reflection; (4) to take the initiative to motivate teachers to meet the needs of the development of modern education. The evaluation principles are active orientation principle, the principle of redevelopment rather than reutilitarian principle, the overall target and timeliness, and process principles [18]. The most obvious difference with the traditional evaluation and the development of evaluation has actively promoted a wide range of evaluation subjects: teacher self-assessment, peerto-peer assessment, expert evaluation, the evaluation of students participation and the community, as well as the promotion of teachers to actively participate in evaluation of changes in the roles of the evaluators which is very important. The evaluator and teacher must look at change from high equality listener and interlocutor so as to create an atmosphere of good communication, so that teachers speak their minds [12]. Developmental evaluation pays more attention to the evaluation of the ethical: Prior to the formulation and design of the evaluation program,there must be an investigation on the needs of teachers and teachers' decide to participate; some communications between the evaluators and the object in front of the classroom observation establish the context, ascertain the teacher's aims and expectations, share the lesson plan, identify potential difficulties and constraints, agree the observation style and the focus, and contract for debriefing [13]. The researchers believe that "developmental evaluation" enables teachers to produce effective internal incentive, self-motivation, arousing in the individual a strong sense of accomplishment, thus fueling self-evaluation and achievements awareness and willing to work hard and eventually produce a certain amount of the incentive effects [19]. At the same time, the assessment of development emphasizes the value of the teachers in 
the school. I believed that individual teachers have the ability to make the right judgments while recognizing the developmental needs of individual teachers and school developmental needs. Therefore, development of evaluation is to promote teacher development, and school needs an effective strategy of unity and integration [11]. Some commentators believed that although the development of evaluation is a more desirable trend of development, its effectiveness also needs strong external support. (1) The strong policy support is an important prerequisite for developing teacher evaluation. (2) It is the necessary condition led by experts for the smooth implementation of developing teacher evaluation. (3) To withstand the test of practice is the touchstone of the development of teacher evaluation to be acceptable for the majority of teachers [20]. That debate has not only led to more of our thinking, but we need the field to make some research and experiments for further verification.

\subsection{The Dispute of Development Evaluation and Reward and} Punishment Evaluation. Some researchers had very different views for the "reward and punishment evaluation" and "developmental evaluation" implementation of the pros and cons with the aforementioned points of view [21]. The researchers believed that our implementation of the development of teacher evaluation in the context of the rewards and punishments of the teacher evaluation system that cannot be canceled, in the implementation of the development of teacher evaluation, cannot completely deny or evade the rewards and punishments of teacher evaluation system [22], the key to the implementation of developmental teacher evaluation is not whether but how to get it linked with rewards and punishments; Simply against each other, the development of evaluation and reward and punishment evaluation represent the lack of combination of education reality dialectical thinking [23]. The researchers believed that the development of evaluation was not irreconcilable with the "incentive" teacher evaluation, but the reward and punishment evaluation was the inheritance and development of teacher evaluation. In theory, incentive teacher evaluation and development of evaluation are split for the purpose of evaluation, and to explore the adversarial relationship is inappropriate, because the purpose of teacher evaluation originally developed and reward and punishment is only a means of evaluation $[24,25]$; Commentators have suggested that the incentive evaluation is educational administrators on teacher supervision and management of services, and the emphasis is on incentives and constraints. However, developing teacher evaluation for the teachers' personal development services, education, guidance, and assistance functions, the two are not in relationship to what western scholars had said, for the conflict between the two was not adjustable. The development of evaluation and reward assessment is not irreconcilable. They can coexist and complement each other under certain condition, form the long-term interests and teacher professional development. Their fundamental purpose is the same and their results of the development itself is the best reward [22]. There were commentators who have made it clear that the two can be combined, researchers with the formula "the motivating force $=\sum f$ (substances stimulate + spirit stimulation)" $[14,15]$, and that the combination of the two "composite evaluation of the teacher evaluation is a rational choice" [26]. There are commentators clearly developing teacher evaluation system to build a combination of evaluation development and reward of the teacher evaluation system and implementation of a 360-degree feedback evaluation and the whole process of teacher performance management and assessment [27]. So, commentators had drawn on the basis of field research that both analysis and combination of the two were entirely feasible to have great significance for the depth of the reform of teacher evaluation [28]. As for the study abroad on the relationship between the two, different commentators draw a different conclusion. Someone said: "UK, US, and other Western countries have tried to "combine" the two teacher evaluation systems and the results were a stricken failure, receiving no expected effect" [21]. Some commentators have claimed that "the reason why combined use of the attempted incentive teacher evaluation system and developing teacher evaluation system was "almost to the brink of collapse" in the developing teacher evaluation in UK and USA, of course, for all of Chinese academic circles, there is a long journey line to go.

3.4. Performance Evaluation. For the definition of performance, Cai has borrowed Murphy's definition-individual's organization or group goals related to behavior [8]. In fact, teacher performance evaluation is only a stage in the evaluation of teachers' career; the evaluation also includes teacher competence evaluation for the preservice teachers and the ultimate effect of teacher effectiveness evaluation. Due to the later start of Chinese academic teacher evaluation researches, the teacher performance was slightly weak. There was no strict distinction between researchers of different types of evaluation, resulting in a mix of different types and functions of teacher evaluation. Thus, teachers validity studies were difficult to draw the correct conclusions. Even for the evaluation of teacher performance, the content did not have unity, the structure was not clear, and, in the formulation of research tools or a simple list of some of the factors or random summarized some of the projects, the lack of a solid theoretical basis was clear [8]. With further research and the introduction of foreign ideas, Cai also complements the definition of performance, the performance of the structure including the provisions of the act and the individual spontaneous role behavior. The former is called the task performance, while the latter is relationship performance [9]. This is the first relationship performance in the country. Cai and Lin through a series of studies, found that the quality of teachers structure theory is the basis of the structure theory of teacher performance, and they defined the quality of teachers as being the sum of the teachers in the educational and teaching activities, to determine their education effect, with a direct and significant impact on the psychological quality of students' physical and mental development. It includes career aspirations, level of knowledge, concepts of education, teaching and monitoring capabilities, as well as education and teaching 
behaviors and strategies. The eventual adoption of qualitative research methods reached the six dimensions of teacher performance: professional ethics, professional dedication, assisting and cooperation, the effectiveness of teaching, teaching values, and teacher-student interaction [9]. For the use of teacher performance evaluation process, some commentators believed that it depends on the theoretical basis, the purpose of the evaluation, the evaluation, the evaluation procedures, and frequency differences to distinguish between teacher performance evaluation and teacher competency evaluation. Then, it evaluated teacher performance implementation of the various stages of effective management, including the management of the preparation phase and implementation phase of the management. Finally, it is the implementation of management, prudent interpretation, and identification of application teacher performance evaluation information [29]. Some commentators believed that in the performance evaluation, it must want to adhere to the principle of "people-oriented": (1) the performance evaluation criteria to set up and choose to adhere to the "people-oriented"; (2) performance evaluation to adhere to the "people-oriented"; (3) performance feedback to adhere to the "people-oriented"; (4) the use of performance evaluation results must adhere to the "people-oriented"; (5) the relationship between treatment evaluators and evaluators should adhere to the "people-oriented" [30]. Guidance of this theory in practice is both beneficial to the development of individual teachers, but it is also favorable for the development of the school.

\section{China Academic Thinking and Critical to the Teacher Evaluation}

4.1. On In-Depth Thinking of the Teacher Evaluation. From the etymological point of view, the Latin original intent of the "evaluation" refers to "strength" and "empowerment"; in other words, the purpose of the evaluation "is not in order to prove, but in order to improve." The most fundamental and one of the direct aims is to promote the professional development of teachers, especially in the professional development of autonomy [31], and evaluation in essence is the formation of a "consultation" and "psychological construct," which adhere to the belief of "value pluralism" and oppose the tendency of "managerialism" [32]. For the reality of teacher evaluation, there had been two opposing points of view: a "locus of control," the typical representative of this view was the emphasis on evaluation of teaching performance of teachers' responsibility system; another was a "noncontrol concept," and it emphasized that teacher evaluation should not value the decisive pressure from superiors, principals, students, parents, and colleagues but should be concerned about the progress and improvement of teachers in teaching [7]. In teacher evaluation, some commentators had suggested that teacher evaluation were not along with ones' thinking, student test scores was not equal to teaching effectiveness, and quantification was not equal to the scientific and comprehensive and may not be fair [33]. In our country for teacher evaluation there are mainly two kinds of orientation: one looked on evaluation of teachers as a measurement and identification of a teacher; another looked on evaluation of teachers as a teacher management means [34].

From the point of philosophical view, different theorists have different thinking perspectives, and commentators from the perspective of hermeneutics assessment believe that the "understanding" and "dialogue" and "showing intersubjectivity" are the basic criteria of teacher evaluation. At the same time, from the philosophical category, the value orientation of the teacher evaluation from one direction to diversities, from the relationship between areas of view, and the evaluation of the two sides from the opposition should be between the subjective and objective towards intersubjectivity; Some commentators after the modernist perspective, to critique and understand the evaluation of teachers, suggest that the postmodern orientation of the teacher evaluation research has great significances. The current teacher evaluation is often evolved into mechanical, meaningless activities, many teachers in fear, suspicion, and hostility eyes to look at for the teacher evaluation. The root cause of this phenomenon is the separation of the main object of the evaluation of modernist orientation, evaluation of the "tool man" hypothesis, as well as quantitative evaluation methods. We need to borrow postmodern ideology, with full respect for the dominant position of teachers in teacher evaluation, and establish a humane view of the evaluation. We could not only just see the evaluation in the promotion of teachers to improve the quality of education "tool," but also go beyond the limitations of this narrow vision of "tools," recognizing that the evaluation should not only need, but also must promote teachers' professional development and personal growth, publicity to promote teachers' personality, and the value of life. At the same time, we focus on the use of qualitative evaluation methods in teacher evaluation [35]. Of course, only he who has a thoughtful understanding of this basic theory can really grasp the principles and methods of the teacher evaluation.

\subsection{Evaluation of Teacher Evaluation Methods and Models.} The findings in China and abroad have shown that a variety of methods can be applied to teaching evaluation, such as teachers' self-assessment, evaluation of teachers files, parent evaluation, teaching evaluation, classroom observation and interview, informal observations, peer review, or peer assessment, capacity test, indirect measurement of student academic achievement, and written materials collection. Another classification can be summarized as classroom observations, clinical supervision, teaching videos, researchoriented checklists, written tests, goal management, job analysis, students' academic achievement, anecdotes, diary, file evaluation of growth, responsibility and theoretical orientation, self-evaluation, peer-to-peer assessment, student evaluation of teacher questionnaires and interviews, and meta-evaluation. East China Normal University's Wang Binlin believed that what was frequently used in our country was the following ten: (1) classroom observations, classroom observations can generally be divided into the classroom 
observations, teaching videos, and teaching observing; (2) evaluation of classroom performance, making teacher-rating scales as a benchmark, and then judging the behavior of teachers' classroom performance; (3) students' academic achievement, also known as value-added method, the main variable is the application of students in a certain period of learning progress time, such as to compare two test scores and their academic achievement, such as employment rates and employment conditions, contest winners, and so forth; (4) growth appraisal; (5) the student/parent evaluation; (6) peer review/assistance, peer review/assistance have counterparts in pairs (inter-professional support relationship, and help each other succeed, and to solve the problem and the lifting of frustration), peer guidance (among mentoring relationship initiative by the expert teachers and new teachers share their teaching expertise), peer discipline (groups of experienced teachers in collaborative reflection, discussion, and reporting, in access to learning new teaching skills and techniques), and other forms; (7) teachers' self-assessment/action; (8) written test/test; (9) questionnaire and interview; (10) metaevaluation [36]. Some commentators had proposed a " 345 " model, including: three-dimensional evaluation criteria, namely, quality, responsibilities, and performance; three types of evaluation method: evaluation of the relative standard absolute criteria for evaluation of intraindividual difference evaluation; thirdorder evaluation method: diagnostic assessment, formative assessment, and summative assessment; four categories of evaluation results: quantitative interpretation, the hierarchical interpretation of descriptive explanation, and attribution analysis; five evaluation subjects: education administrators, peers, teachers, oneself, students, parents [37]. However it should have been noted that the evaluation methods and models which have different applications to the subjects needed to make a choice to be used in the evaluation.

4.3. Analysis to Evaluation of the Principal Part. The main differences of teachers' evaluation lie in the role, status, abilities and their experience. At this stage, in the discourse world of the teacher evaluation, in general, there are three types of discourse systems. One is issued by the administrator of the power evaluation of discourse. The second type is manufactured by the experts and scholars from a variety of academic discourse, to convey a rational "logic of power." The third is a class issued by the teachers themselves in individual words; it is really the way to convey their personal lives on the value of the work relationship and the value of the phenomenon in a specific organizational context holism and practice, as reflected by the power of a metaphor [31]. At this stage, Chinese and foreign scholars are fully aware of the necessity and importance of the diversification of the principal to participate in teacher evaluation. In addition to the traditional leadership evaluation, expert evaluation, administrative staff evaluations, more discussion of selfevaluation, peer evaluation, and student evaluation, the following is a brief analysis of the latter three. The first is the self-evaluation, which is a reflection of the self-evaluation
[32]; it is an important foundation for teachers' professional development $[38,39]$. Commentators have suggested that self-assessment skills enable teachers to get insight, understanding, and interpretation from the other aspects of materials, and conducive to the role of teachers internalized, intrinsic motivation to inspire teachers, to encourage teachers to actively participate in the evaluation process, a sense of ownership and democratic atmosphere, you can broaden the evaluative information collection channels, improve the reliability of evaluation results and effectiveness, improve teachers' self-evaluation, to enhance teachers' professional standards. But for good self-evaluation, it must firstly resolve the following issues: (1) self-evaluation in the reference standard; (2) psychological concerns in the self-evaluation; (3) self-evaluation skills and the self-fantasy problem; so, evaluation before the training is very important. Second, peer review includes school teachers-school teachers or expert evaluation [40]. Peers as professionals, they understand the nature of the profession and the problems in the evaluation of academic standards of teachers and capabilities, peers at the most advantageous position; they are more familiar with classroom activities, teaching materials, as well as the requirements for teachers evaluators; most teachers improve their teaching duties by specific and practical advice. But others questioned the reliability and validity of peer review to solve this problem from two points to spare paper: first, to make peer evaluation activities organized to provide appropriate evaluation criteria and scale, carefully composed of a balanced assessment of the panel of experts; second is to broaden the channels and methods of evaluation. The third is student evaluation. The students are the direct consumers of educational products and teaching achievements firsthand. The student evaluation of the teaching process and its effects is important and unique. If we make appropriate and better organized evaluation criteria (such as a description of the purpose of evaluation, anonymous, etc.), evaluation of the students can reflect part of the real situation of the teaching process. Student evaluation should also pay attention to four issues: (1) to overcome the contradictions and conflicts that exist in the evaluation; (2) the scientific design of the scale of student evaluation of teaching; (3) the analysis of a number of factors that affect the results of student evaluation of teachers; (4) the timing of the student evaluation of teaching [41]. Also, someone had worked out the structure of the theoretical framework of student evaluation: professional ethics, dedication to duty, assisting and cooperation, the effectiveness of teaching, and teaching the value of teacherstudent interaction [10]. Besides, the others can also be called to evaluate the difference between self-evaluation and student evaluation. Some researchers believed that others' evaluation can reduce the separation and that self-evaluation is a pathological cause of the existing educational evaluation [42]. This study suggests that the judgment of others or the self-evaluation is the application of environmental random application only to produce counterproductive results.

4.4. Critical to the Development of Teacher Evaluation Standard Error Tendency. Wang believes that now there 
is a number of erroneous tendencies in the process of developing teacher evaluation criteria as follows: (1) copycat, in other words, some schools always want to find readymade or the applicable teacher evaluation standards from foreign literatures; (2) the teacher evaluation criteria of "thousands of people a pattern"; (3) using "antiquated" teacher evaluation criteria. Teacher evaluation criteria should be changed with the times, fully reflecting the times and reality; outdated teacher evaluation criteria should have appropriate adjustment; (4) "unrealistic" teacher evaluation criteria. Teacher evaluation criteria should be accept, and after efforts one should achieve the standard; (5) purpose of the teacher evaluation criteria. In the development of teacher evaluation criteria, be sure to first clear why the evaluation is made, fully embodying the purpose and relevance of every teacher evaluation; (6) "overly soft" teacher evaluation criteria. "Overly flexible" teacher evaluation criteria must be further decomposed and refined, until you could operate [43]. Some commentators have suggested that the current implementation of teacher evaluation in China, often with the administration tendency, one-sided emphasis on one mode, step in step, and without considering the differences in areas, units, and subject categories, the system is too stiff. Definition is as follows: (1) indicators are too far in pursuing a comprehensive and difficult-to-differentiate level of the evaluation object; (2) deliberate pursuit of the quantitative evaluation of the information is difficult to effectively reflect the essential characteristics of the evaluation object; in the teacher evaluation, it had been filed, and criticism was the number of indicators, which was too much emphasis on the utilitarian and practical value [44]; (3) evaluation methods in the indicators, quantifiable mode, too much emphasis on redistribution, ignore the evaluation standard [45]. Therefore, teachers in the implementation of the constructive or developmental evaluation should master the following three principles: (1) evaluation and not that the person can protect teachers' self-esteem, enabling teachers to lay down their psychological burden, calm face of the gain and loss of education, and have a normal state of mind; (2) the evaluation process around specific issues for communication and discussion to ensure that the interaction between teachers promoted and improved work together, causing the formation of a good school atmosphere; (3) evaluation is not confined to the established standards, to avoid the closed and rigid standards, conducive to the development potential of teachers, to encourage teachers to reform and innovate [34]. From the evaluation process, standardized operating procedures of the teacher evaluation are not enough; it is difficult to achieve the established evaluation goals. The lack of dynamic track evaluation could not provide effective feedback to teachers [46]. Of course, criticism is the driving force for development, and construction is the ultimate purpose of criticism. This study suggests that increasing the constructive elements of criticism is a more important research areas in the current teacher evaluation.
TABLE 1: Foreign literature numbers in the teacher evaluation.

\begin{tabular}{lccccc}
\hline Nation & Number & Percentage & Nation & Number & Percentage \\
\hline USA & 313 & 62.98 & Germany & 8 & 1.61 \\
UK & 94 & 18.91 & France & 6 & 1.21 \\
Japan & 28 & 5.63 & Singapore & 6 & 1.21 \\
Canada & 13 & 2.62 & Russia & 2 & 0.40 \\
Australia & 12 & 2.41 & Finland & 2 & 0.40 \\
Korea & 12 & 2.41 & India & 1 & 0.20 \\
\hline
\end{tabular}

\section{Studying and Introducing UK and USA Theories}

Throughout the history of the development of Chinese education, there are many theories originated in the introduction of foreign theory, and the same was true in the area of teacher evaluation. Sun He, Liaoning Normal University, for example, introduced the theory of the United States, Britain, Finland, and other countries in the field of teacher evaluation. At the same time, Cai Min, Liaoning Normal University, has played an important role in the introduction of the theory of the United States and Canada; they are the top scholars in this field. In this study, through statistical analysis, we finally listed the number of literatures table of study abroad in teacher evaluation.

From Table 1, it can be clearly seen that in the promotion of teacher evaluation on foreign experience and theory, UK and USA are overwhelmingly dominating; so in this part, we want to make a brief summary in theory and experience of UK and the United States.

5.1. The UK. UK's formal teacher evaluation was not a long history, from the literature informed, from the 1970s onwards. Some schools had voluntarily carried out some tests, and the evaluation of this period was a control evaluation system; the British Federation of Teachers before the government developed its own evaluation of the various measures of teachers and reward criteria. Former British Prime Minister James Callaghan Ruskin had given a speech in Ruskin College, and the content was also relevant. The rewards and punishments evaluation policy continued until the 1980s. However, the teacher evaluation of official government was proposed in Teaching Quality of the 1983 White Paper on Education and in 1985 the book Make School Better, soon after the United Kingdom Education and Science seriously paied attention to the teacher evaluation report submitted by the 1986 Advisory, Conciliation, Arbitration and Services Working Group (ACAS), and six counties in the United Kingdom in 1987-1988 had been tested [47]. The summary report submitted after the trial has become the prototype of British 1990s teacher evaluation guidance document. This report was not only one of the important theoretical basis to 1989 Education Reform Act, it was also one important theoretical basis of the July 1991 Education (School Teacher Evaluation) Ordinance released by the Ministry of Education and Employment (the latter required across 
England to establish a teacher evaluation system in public elementary and secondary schools).

The clear purpose of this guidance document proposed by the teacher evaluation is abandoning the judgment of teacher performance that is not based on rewards and punishments for the purpose of teacher evaluation system, but the diagnosis and the purpose focus on supporting teachers' professional development, the schools' progress, and improvement of teaching quality [48]. This evaluation was a combination of qualitative and quantitative rating processes [38, 39]. This evaluation process was divided into three phases: preparation, implementation, and results. (1) During the preparation phase, it would be clear that the evaluation process is open to the evaluators and the establishment of mutual understanding on the basis of the evaluation process; it should be an important part of the school's overall teacher development strategy. Also, it requires the personnel qualifications and evaluation methods in evaluation, as well as formal training to the evaluation and assessment staff. (2) In the beginning of implementation, the two sides together determine the evaluation purpose, the scope, the calendar, and so on. In the implementation of the evaluation, self-evaluation, personal evaluation, and classroom observation are all important parts, but the formal implementation began from the conversation, the first assessment of teachers to conduct self-assessment and classroom observation, followed by evaluation of the object leadership, colleagues, students, and parents to conduct a survey to complete the evaluation report of a paragraph [49]. The talks of evaluation involve teachers in both teaching and supervision duties, job performance, and professional development requirements and recommendations of the school. The contents of the evaluation report should also include the addition to the summary of individual results and also include the establishment of the teachers to achieve developmental goals, noting the principles of confidentiality. (3) The complete report is not the end of the evaluation. In the evaluation, finding problems is more important, maintaining the continuity of the relationship between the evaluators and assessment of teachers, then holding several fixed talks after mutual agreement, professional development, and training, and giving appropriate support and encouragement. In the middle of the first and the second year after the first evaluation, also two reevaluations also are needed, those are midterm reevaluation and the overall objectives of the reevaluation.

The development of teacher evaluation policy described in the previous paragraph was implemented by the British Conservative Party in the early 1990s, but the later of 1990s, as the Labor Party took place in a larger reform in December 1998, the Labor government made an implementation of Performance Related Pay that was a "compromise" evaluation policy, and the Green Paper published in that month the English teachers' professional modern PRP policy linked to the salaries of teachers and principals or chief instructor and performance. The Labor government claimed that this evaluation system has a "dual function": first, the decision in accordance with the quantitative indicators of teachers' salaries was to promote the personal and professional development of teachers $[38,39]$. Its purpose was the appropriate reward to those who have made important contributions to school success principals, to maintain the teaching profession sufficiently attractive to talented young people, reward excellence, and promote professional development. The PRP's ultimate goal was to improve the level of education. The PRP staff includes the government officials, external supervisors, principals, teacher team leaders, and teachers. The evaluation process was divided into three steps: planning, and assessment, operational monitoring, and discussion and review. In short, the aim was to improve management efficiency through management by objectives, scientific management, and emotional management, and to achieve good results in a period of time. The PRP supporters believe that such an evaluation system should achieve such objectives: (1) to better stimulate the teachers' sense of responsibility; (2) enhance the impetus to the development of teachers; (3) the teachers' job satisfaction; (4) to strengthen the teachers' personal goals with the school overall objective of integration; (5) to maintain highquality teachers' structure [50]. However, some negative impacts appeared: (1) this evaluation system was destructive of cooperation between the teachers; (2) it brought a greater controllability of the school bureaucracy. Later, this evaluation system has been suspected as a performancebased evaluation system.

However not lasting long, in 2000, the United Kingdom Ministry of Education and Employment issued a circular performance management in the primary and secondary schools; it introduced a new evaluation systemPerformance Management evaluation system, the system which was rapidly promoted in 2001 . The system core was through the teacher evaluation law which was institutionalized and standardized to provide the necessary supports and helps for teachers, improving teachers' teaching ability and level, thus achieving the promotion of the school's efficiency and raising the level of ultimately improving student which wasthe purpose of academic achievement [51]. The system was an organic integration of the reward and punishment evaluation systems and the development assessment system. It also further improved the evaluation system of PRP. The British government attached great importance to the new evaluation system, since the Education Bureau of Standards (OFSTED) (responsible for the evaluation and supervision of the primary and secondary schools) and the following set up a three-tier responsibility of institutions around the public schools: local education authorities, the board of directors of each school, and schools, and cleared the respective responsibilities [52]. The new evaluation system placed more emphasis on the science of teaching of teachers and learning of students, concerned about the organization of classroom teaching and student interaction and exchange. For effective classroom teaching, the British government proposed eight criteria as the basis as follows: (1) effectively plan for teaching to develop clear goals understandable; (2) have good subject knowledge and understanding; (3) use of teaching method which can lead all students to learn effectively; (4) to organize the students to maintain a high level of interaction; (5) give a comprehensive evaluation of students' academic; (6) allow 
students access to a wealth of learning outcomes as much as possible; (7) effective use of time and resources; (8) effective use of homework to reinforce and expand learning [53]. The new classroom teaching evaluation system was based on the school as the basic unit. The teacher group leaders and teachers jointly participate in the evaluation mode. It persist in people-oriented development at its core, focusing on teachers' personal value and professional development, to cash a methodological pluralism and individual differences.

So, after the study summarized the history of the English teacher evaluation system, the researchers had believed that the main line was from reward and punishment evaluation to the development evaluation and then to performance management evaluation process [54]. In fact, the whole world in the field of teacher evaluation was similar.

\subsection{USA}

5.2.1. The Development Path of USA Teacher Evaluation. Compared with the UK, the formation of the teacher evaluation system in the United States was much earlier. It can be traced back to the colonial period in the 19th century, having the management authorities in the school system to appoint a specific leadership or full-time management for teacher evaluation. In 1925, the school system of the nation's major cities had been beginning to carry out a variety of teacher performance assessment [55]. In 1952, the US government established the National Teachers Identified Council, and in 1954, established the Teacher Education Accreditation Board, so as to unify requirements to the state teachers. The evaluation in the 1950s was a "performance pay system." It was the basis for performance evaluation to determine teachers' salaries and allowances. Since 1977, the United States began to have the ability test for teachers, launched in most states, in addition to individual states to self-test the questionnaire. The majority of states have adopted the National Teacher Examination as the test standard.

Time into the 1980s, the US government has already made substantial progress understanding the teacher evaluation. Only the nurturing and protection of excellent teachers, could help the United States to solve the education crisis, which was written in the 1983 government report Nation in Risk: The Imperative for Educational Reform. In 1986, Carnegie report State to Prepare Teachers in the 21st Century created a national teachers' qualifications review bodies to develop a unified national eligibility criteria for high-quality teachers [56]. As the United States is purposing decentralization, it makes states, school districts formed different purposes, different methods, and different evaluation criteria for distinctive teacher evaluation system. After several years, the US government in the organization and implementation of teacher evaluation has been institutionalized and standardized [57]. Overall, in the early 1980s, the United States in the teacher evaluation system had focused on "developmental evaluation." It was a development in the formative evaluation on the basis of evaluation. It was also a performance-based developmental evaluation system (PBDES). The implementation of the program was divided into seven steps: (1) to discuss the purpose of the evaluation, the evaluation model, as well as related terms, and drafting the report of an evaluation purposes; (2) develop performance criteria and descriptors; (3) collection of teacher behavior information; (4) make the classification of information, sorting, the formative data form; (5) convening the formation of meetings; (6) a discussion of indicators to identify principals and teachers to develop a development plan; (7) make the formation of the summative evaluation [58]. The summative evaluation is a composite index based on work experience, degree and performance evaluation is used to determine the pay raise, promotion methods, designed as reward and punishment mechanism to motivate teachers to improve teaching quality [59]. Such an evaluation system falls in three main areas to evaluate teachers: national teacher examinations (tests could be divided into nationwide, statewide tests and the range of the school district tests) [57], student achievement test scores, and teacher performance in the classroom [55]. However this was biased towards a certain extent, while filling the teachers were in the care of their own remuneration, while ignoring the improvement of educational practice, and did not trust such an evaluation system, and did not solve the teacher shortage and improve the quality of teachers of the intended purpose, so the difference in promotion system was abolished in 1992.

Then, the states have put forward their own teacher evaluation systems, though that was formed of a better situation of flourishing. For example, Louisiana had established a learner-centered classroom evaluation system-teaching evaluation and assessment system (the system for teaching and learning assessment and review, STAR), while Florida had established a vocational assessment and evaluation system (the professional assessment and comprehensive evaluation system, PACES). At the same time, from 1987 to 1995, the National Board for Professional Teaching Standards (NBPTS) had successively implemented a series of detailed criteria to identify and certify skilled teachers in 27 disciplines. Its five core characteristics are as follows: (1) responsible for the students and their learning; (2) familiar with the subjects which they teach as well as guidance on how to impart knowledge to students; (3) responsible for managing and monitoring student learning; (4) to carry out their teaching practice systems thinking and learning from experience; (5) to become a learning team [60]. From 1995 to 2005, the NBPTS of the total number of teachers was 47,507 people. In 2007 , application for a certificate had reached 99,300 people, including 63,800 ultimately approved [61]. In addition to the previously mentioned NBPTS, the institutions of the United States at this stage in the evaluation of teachers were the National Teacher Education Accreditation Council (NCATE) and the US Quality Teachers of the Credentials Committee (ABCTE). The former was established in 1954, aiming to develop and improve the standards of the accreditation of teacher education, in order to ensure the quality of teacher education providing the professional judgment standard that was mainly responsible to monitor the quality of preservice teacher training. The standards set in 2006 a new task entry certification of new 
teachers to assess and promote its further development. The ABCTE was founded in 2001 and was set up jointly by the National Council on Teacher Quality (NCTQ) and Education Leadership Council (EIC). It is a new teacher certification organization. There are two of its certification objects: one is the entry of new teacher certification and quality certification, and the other is experienced teachers.

In 2001, the Bush administration signed the document "No Child Left Behind" (NCLB) to distinguish standards of new teachers and in-service teachers, corresponding to development of highly qualified teacher standards, while Interstate New Teacher Assessment and Support Consortium (INTASC) responsible for the new teacher standards of the developed stage of basic education had been formed [62]. US teacher evaluation at this stage presents characteristics of the "performance" system, focusing on student learning, with the overall objective to require all US primary and secondary students in reading mathematics and science achievement to reach the level of proficiency at the time of 2014 [63], and the introduction of NCLB makes the United States present the new changes in three aspects of teacher evaluation: (1) the expansion of the connotation of teacher performance, and the promotion of the Tennessee Value-Added Assessment System in the US (TVAAS) [64], and also set up systems of accountability between the states, school districts, schools, and teachers to implement the responsibility system, the signing of the assessment agreement; (2) to broaden the entry caliber of teachers and is committed to improving the quality of teachers; (3) states widespread use of individual monitoring and evaluation system, known as Addison the Central Supervisory Union (ACSU) and Maryland Montgomery County Teachers' Professional Growth System (PGS) [65]. NCLB can be regarded as an education reform bill which made the teacher evaluation theory have a full range of change as follows: (1) extending the purpose of the evaluation played a variety of teacher evaluation utilities; (2) absorption of multiple subjects involving the establishment of democratic consultation and evaluation mechanisms; (3) broadening the collection of information channels and scope of teaching materials, the ability of performance, professional achievement, professional development activities, student academic status to collect data, and evaluation of evidence of a more comprehensive objective; (4) paying attention to teachers' differences and establishing several categories of evaluation criteria; (5) strengthen the training of personnel, improving the professional standards of teacher evaluation [66]. From this, the promulgation of this bill has a positive historical significance.

This stage, the core content of the teacher evaluation system, was mainly reflected in two aspects: first, the public accountability of the teachers, and the other from teachers to improve the development needs of the professional level [55]. The teacher evaluation was characterized by rendering anti-specialization trend, evaluating teachers in accordance of their aptitude (e. g., with a different evaluation criteria to evaluate teachers in different levels of development, emphasizing diversification, value-added assessment, portfolio rating and individual supervision in a variety of ways), emphasizing on the developmental assessment (that is to say, the teacher evaluation is not for proving but for improving and is not for dealing with the teachers but for teachers) [67], integrating teacher evaluation and teacher organizations development with school improvement, developing the regional teacher evaluation standards, focusing on the combination of quantitative and qualitative evaluation. The ideas of evaluation like the British also attach great importance to teachers' classroom teaching and the center of the classroom observation from the teachers' teaching to the students' learning and establish the evaluation mode and evaluation system based on student-centered techniques. The System for Teaching and Learning Assessment and Review (STAR), implemented in Miami, Florida, and Professional Assessment and Comprehensive Evaluation System (PACES) were the famous systems [68]. Taken together, the evaluation model is mainly of seven kinds: (1) teacher trait model, (2) process-oriented model, (3) duties-based evaluation, (4) accountability model, (5) goals-based evaluation, (6) professional growth model, and (7) hybrid model [55]. We had summarized its characteristics: (1) require teachers with multidirectional and forward-looking timing; (2) concern the appropriateness between the teachers' teaching and student learning; (3) emphasize on teacher professional; (4) require teachers to shoulder the responsibility of the educational evaluation; (5) stress teachers shoulder on many responsibilities to the students [69].

For teacher evaluation, the United States at this stage had a clearly distinguished hierarchy. Even they clearly put forward a differentiated evaluation system, it is a system according to the reality situation and demand of different teachers to formulate explicit teaching standards, to use different evaluation procedure and to complete by professional evaluators. Its purpose is to evaluate the quality and job performance of teachers. The so-called "distinguish" is the "difference." The direct goal of the evaluation is not to compare the level of teachers, but to respect the value of diversity and individual differences in the evaluation, under the premise of the recognition of differences, to discriminate pros and cons of teachers' work to achieve the two assessment purposes of ensuring student academic achievement and promoting professional development of teachers [70]. There are different evaluation criteria for the newly recruited teachers and skilled teachers. For new teachers is to meet the New Teacher Induction Program (NTIP) standards. At the same time, with special emphasis on the new teachers' ability to use educational technology. U.S. Agency for International Society for Technology in Education (ISTE) belongs to the Title of Identification with the Professional Standards Committee had promulgated National Educational Technology Standards for Teachers (NETST), has mainly used to preservice teachers training and certification guidance. This standard encompasses 6 quality dimensions and the 23-level indicators. In 2008, ISTE also had promulgated NETST (2008 edition) for guidance training of the technical capacity of the education of new teachers in the situation and reducing the quality dimension and level indicators for 5 dimensions and 20-level indicators. Throughout the evaluation process, the National Council for Accreditation of Teacher Education (NCATE) had undertaken specific 
work and the National Educational Technology Standards for Teachers Resources for Assessment as the guiding standard [61]. For a skilled teacher, in California in 2006, Performance Appraisal of Experienced Teacher (PAET) had promulgated. PAET provisions once in every five years, and the United States Professional Teaching Standards (NBPTS) provide contents in 5 areas: a sense of responsibility and contribution, knowledge and skills, teaching practice, teamwork, and professional development. The evaluation committee was composed of school principals, vice principals, educational supervisors, and experts. PAET implementation of procedures covers the following steps: classroom observation before the meeting, classroom observation, classroom observation after the meeting, the summative evaluation, and additional evaluation (second evaluation and third evaluation) [71]. From this, teacher's classroom teaching was the core content of the skilled teacher evaluation.

5.2.2. Teaching Portfolio Assessment. Currently, in the United States, there are a variety of methods for teacher evaluation, including teacher self-evaluation, peer evaluation, student evaluation, student achievement, assessment, teacher interviews, spot steering checklist assessment, written tests, job analysis, classroom observation, teaching video analysis, teaching $\log$ analysis, file analysis, and questionnaire survey [67]. However, the teaching portfolio is the most impressive. Also, our teacher evaluation methods most widely research about America in recent years, and the following is a brief description.

Selective collection of teaching information, teaching portfolio has been widely used at all levels of nationals, states, districts, and schools. NBPTS has looked on teaching portfolio as the basis for teacher license reissued. Many school districts are using teaching portfolios to identify outstanding teachers. As early as 1988, Lee Shulman had proposed that in the teachers' assessment, the portfolio should be used in conjunction with traditional written tests and classroom observation. Overall, the portfolio is the integration of forms of teaching. Its characteristics are as follows: (1) including the work of teachers and students; (2) structuring and purpose; (3) being able to display the time of teachers in the context of teaching and learning and experience; (4) having a reflective and collaborative approach [72]; (5) reflecting the authenticity and richness (6) showing a strong subjectivity [73]. If you want to build portfolios by different purposes, it can be divided into three categories: learning portfolio, assessment portfolio, and employment portfolio, but, in fact, the teacher's portfolios are two or three kinds of combination. According to their nature, it can be divided into processbased, results, and showcase [2-4]. The rules to follow for the development and utilization of the portfolio are as follows: (1) establish the purpose of the development portfolio, (2) collect materials, (3) organize materials, (4) write reflective description, and (5) show feedback and revise [74].

With the penetration of scientific and technological strength to education and the continuous support increasing, recent years electronic portfolio evaluation methods happened [75]. Compared with the traditional portfolio assessment, electronic portfolio's assessment information is more personalized, with presentation and display faster and more convenient and diversified, the more permeability of the evaluation, the evaluation of the subject and the way is a more diversified, more contribute to the sharing and exchange of information, more openness, more development potential.

Overall, the teaching portfolio can be used for summative evaluation and can also be used for formative assessment and self-evaluation. In practice, portfolio evaluations are the following: seminars, interviews, law, narratives, written evaluation, and answering the question. As a new evaluation concept and method, portfolio assessment shows the following unique advantages: (1) this is the best presentation of a teachers' teaching experience, fiting the concept of Connery educational narrative to explore; (2) make a good qualitative evaluation and quantitative evaluation fusion together; (3) a combination of diagnostic assessment, formative assessment, and summative evaluation of the characteristics; (4) a combination of teachers' self-assessment, others evaluation, and expert evaluation of the characteristics [76]. However, it also has more obvious shortcomings. The development portfolio is time-consuming, teaching equipment are higher, and it requires a large amount of costs for support.

\section{Limitations, Conclusion, and Suggestions}

The study has several limitations. This study is a generality summary of Chinese academic research in teacher evaluation at home and abroad in the past three decades. Even though we have gathered a lot of literature, there are still some valuable data which were not covered, especially those published in later writings we could not timely find, for which we deeply regret.

Here are some inspirations derived from the previous study and put forward in to some suggestions.

6.1. Clearing the Development Path and Trend of Teacher Evaluation in China and Abroad in the Future Is an Important Magic Weapon to Promote the Teachers' Evaluation of Research and Practice Development. Through the earlier discussion, we could see that domestic research process in the field of teacher evaluation has far lagged behind UK and USA; the main focus was still stuck in the quagmire in the theory of entanglement. In fact, the theory is only an assumption, an abstract of mimicry; in reality, the real evaluation model which should be fully in line with a theory does not exist. Moreover, there is no difference in choice of a mode good or bad, as the only distinction is being appropriate or inappropriate, just as what Maxwell said: "the assessment should be reasonable assessment instead of the correct evaluation." Theoretical model of the most questionable in the eyes of ordinary people in some environments is the most appropriate, and the best theoretical models could be not "one size fits all," so that there is no truly the most perfect theory. Blindly pursuing the most perfect theoretical model could only make themselves into the theory of entangled. In addition, according to the theoretical development of teacher 
evaluation in UK and USA, it could make us realize that the development of the theory of teacher evaluation is a multidisciplinary work together to create the theory of crystallization. It is a complex integrated management, sociology, and systems disciplines thinking. Of course, in the case of focusing on individual differences, as an evaluator, he or she need to be aware and understand a certain amount of theories of various disciplines of the subject teachers, so that they are not "hollow" meaningless evaluations. Thus, the development of teacher evaluation system not only for teachers need a new subjects. It also needs evaluators and researchers to continue reinforcing their own knowledge to carve their own evaluation capacity and research capacity in practice, thus promoting the overall progress of the evaluation.

\subsection{The Enlightenment to Chinese Teacher Evaluation from} the Experiences about the Teacher Evaluation between Britain and the United States. From the paper it can be found that the British teacher evaluation has some distinctive features, the maturation of these practices could become our practice guide. (1) The correct purpose of evaluation is to stimulate teachers' teaching enthusiasm, to enhance teachers' development, promoting teachers' sense of responsibility and a sense of well-being, to promote the school resources integration, and maintain that the school has a vibrant personnel structure and so on. (2) The institutional of evaluation is that there should be a stable legal protection to teacher evaluation to form a standardized structure and operation mode, where all teachers understand the evaluation of positive significance and the responsibilities and rights of both sides. It also should have provisions' institutions in the evaluation staff hiring, training, and assessment. (3) The stages of evaluation are next. Evaluation on teachers is not accomplished at one stroke things and not put things right once and for all things, it is something ongoing and focused on long-term development. In the UK, the evaluation generally was divided to three stages of planning, implementation, and results processing, and each stage has a certain mode and principle. (4) The evaluation principles generally include the development, objectivity, comprehensiveness, democracy, scientific, and confidentiality. (5) The sustainability to evaluation is next. The teacher evaluation is not a complete thing. The followup, constant feedback and consultation, as well as the long-term cooperation and exchange are very necessary. The characteristics of persistence would also become the important support of teachers' professional development.

Of course, the experiences of America could also become our useful lessons. (1) Social organizations active participation is tackled. Compared with China, the United States has more social organization to fully participate in the teacher evaluation activities, such as NBPTS, NCATE, ABCTE, and INTASC. There are lots of human resources in Chinese education. It could set up many organizations of the specialized teacher evaluation and development, and after authorized, they could do continuous and comprehensive evaluation to various educational elements. These professional organizations to contribute ideas for the development of the national or local education, professional standards would reduce the number of mistakes, reducing unnecessary consumption and saving the cost of education which is more conducive to sustainable development. (2) The diversification of evaluation method is next. The teacher evaluation should be standardized and diversified. There should be classroom observation, face-to-face interview, ask the students, access to files and other forms, value-added assessment, portfolio rating, and individual supervision mode. Teacher evaluation should suit one's measures to local conditions; it differs from man to man, in the different stages to proper use of different methods. (3) Clear and detailed index is an important base to comprehensive evaluation. In the United States, the evaluation of teachers is to pay attention to the clarity of the index and operability, such as in a teacher file cover evaluation templates, which includes teaching responsibilities and goals, outline, readings, and assignment and exam, to the way of improving company evaluation, student evaluation materials, teaching video, student achievement, the teaching effect of evidence, and the future of the teaching goal of concreteness content; [75] (4) Pay attention to the service functions of evaluation. The basic purpose of American teacher evaluation is to help teachers improve. The core of the improvement is to increase teachers' knowledge, cultivate the teaching skills, increase their professional judgment ability, and create better ability to solve problems under the condition of fully grasp the situation. Based on teachers' current development levels, the purpose is to transcend current and to provide good service for teacher professional development. (5) Some summaries and guidance of the national level are highlighted. In the United States, there often promulgate periodic government education files or education reports; it would become the action guides to the next step education development, such as A Nation Prepared: Teachers for the 21st Century, A Nation at Risk: The Imperative for Educational Reform, and No Child Left Behind. These files contain both the policy proposals and the development goals; they are the programmatic documents of national education development. "Stones from other hills may attack the jade"; learning the mature experience of UK and the USA would let us work less detours, and it would provide good references and important enlightenments for the formation and development of Chinese experiences.

\subsection{Pay Attention to the Cultural Differences at China and Abroad, Creative Construction "The Evaluation Model of Chinese Characteristic". History is a mirror, and the textual research and research for the historical facts would be a road direction for the future. However, the course of foreign history would not necessarily appear in the domestic again; because education is a factor of the national culture, national education obviously reflects cultural differences. The development of the education is the important base of the revitalization of the national culture, and these two are in complementary relationship. Education is not only to the development of the reform and innovation, but also to better inherit historical tradition and excellent cultural achievements. So, the reference of foreign experience at the same time must pay attention to the cultural differences and}


historical condition, avoid appling it mechanically, or use impractical means to solve a problem. Of course, there exists a large number of common culture, and it would become the important nourishment for the mind in the construction of China's education experiences.

It can be seen from the development model of American teacher evaluation, in addition to individual "top-down mode," that there are many important modes, and the highlighted are the "bottom-up" forms. Over times, governments around the spontaneous formation "self-model" the ideology of "self-development characteristics," in stark contrast with some of our places by "mindset" models. The enlightenment for us is that Chinese teacher evaluation system should highlight the "local characteristics" and "school feeling characteristics" in construction with Chinese characteristics, teacher evaluation/methodology, and process/system, which requires the provinces, cities, counties, school educational administrators, and classroom teachers to have courage to stand up, to have courage to engage in innovation for practice, just like around the thriving economic model, and to strive to develop.

This study suggests that, from the overall speaking, we can start from the following two aspects. On the one hand, complement and perfect the education evaluation laws and regulations. The existing education laws, such as the Education Law and the Law on Compulsory Education, have a specific statement of educational evaluation, but the documents related to the teacher profession evaluation are few, and some rules of detailed provisions and local evaluation regulations have not been issued out. Comparing with Britain and the United States on education evaluation legal, China's is slightly rough. It needs to perfect and refine relevant policies and regulations and improve the guidance and operability of the education evaluation work. On the other hand, perfect the mechanism of evaluation personnel selection and appointment. From the part of the system, personnel is the most important factor. Reasonable selection of evaluators and appropriate appointments is a prerequisite to achieve a good evaluation effect. Detailed stated, it should be divided into set position, selection, hiring, training, evaluation, and dismissal. (1) Set position focused on the evaluation of personnel in the state system. The quality of evaluators outweighs the quantity, it will be better to have 1-2 persons in each discipline on the county-level and some school teachers and the community workers could be employed to attend the evaluation work. (2) Selectionid tackled. According to the law to the public members for the recruitment evaluation, it should choose talents who have both ability and integrity, the hard work, the courage to uphold truth, the pioneering spirit of the people. Choice of teaching and management of prominent persons strictly prevent opportunistic into the mix. The selection can be divided into two kinds of nominations and exams to fulfill the standardization propaganda, publicity, and reporting system. (3) Employment is next. To adhere to the principle of "who do not understand educators should not" It is adhere to the principle of that who do not understand education should not be involved. Learning from the agency selection mode of the national school inspectors, the national evaluators could work for five years every session, and it could serve two sessions; provincial, county-level evaluators could work for three years every session and keep three sessions. The evaluators' treatment should be done in accordance with the level of national civil servants. Proper complementary mechanisms should be established to supplement the temporary dismissal or loss of vacancies. (4) Training is important. It should conduct a pre-job training and regular in-service training. It should gradually establish comprehensive three evaluation staff training and the management mechanisms to maintain good operating condition. The professional construction of the evaluation organization should be strengthened, which includes the professionalization of ideas, the work process, the program, the skills and the system. (5) Assessment is crucial. It establishes evaluation system of staff professional quality appraisal and administrative qualities. All evaluation mechanisms must realize the duty and responsibility (the area of responsibility can be divided) and efficiency. It could exchange job or change treatment or change benefit according to the evaluation of benefit. Evaluation mechanisms should reflect the principles of democratic participation; there should be the first-line teachers and students and parents participation, evaluators may also implement a cross-evaluation mechanism. It should implement appraisal according to the development and change of one's responsibility. (6) Dismissal is next. It should dismiss the person of the failed, dereliction of duty, fraud, abuse of power, and bribery to combat retaliation evaluators. In short, the evaluation could not have a superior sense; it should be down-to-earth showing people's sense of responsibility, sense of mission, and improvement together.

\subsection{Educational Administrative Departments Should Give} Full Play to the Guiding Role in the Teacher Evaluation. In China, the main education implementation is based on the pattern of the national schools; therefore, the educational administrative departments would undoubtedly have the very important position in the field of education. Attention to its important position at the same time, its important role is the correct understanding of the way. (1) Evaluation is an activity which needs to emphasize the knowledge and ability, so it needs rigorous training to the evaluators (and their role is not only the teachers' evaluation, the most important is feedback and theoretical and technical guidance for teachers). In other words, the evaluation activities are not only to improve the ability of the teacher being evaluated, but also to improve the evaluation of the ability to exercise the evaluation of a number of highly qualified personnel. (2) As the intermediary of the contact, it needs to broaden the channels of communication theory class and practical class. The best way is to establish the US cooperation system, or to sign a "coaching agreement" under the arrangements of the executive branch, for research institutions further enhance the theoretical level and get a good practice for primary and secondary schools, so as to achieve a win-win situation. (3) For the education administrative departments, the specific sense of reward and punishment evaluation is also very 
reasonable, for the entry evaluation of teachers, in line with the concept of the selection of talents, is to bring unqualified teachers to stop outside the door of the teacher groups, even in evaluation practice of beginning teachers, to be persuaded to "withdraw" a number of unqualified teachers. Of course, for the newly included teachers, ending an evaluation does not mean a historic task completed, but the stage to give a definition. The means of the evaluation has not only rewards and punishments, but also the development of the concept; in fact, this study believes that the performance management practiced in UK and USA also contains the ingredients of the rewards and punishments. "Lagging behind [sic]leaves one vulnerable to attacks" is a well-drawn truth by the history test, and the development of nondirectional would walk into anarchy. (4) Concerning evaluation guidance for teachers' professional development, educational administrative departments should play an important role to lead the road to the track of self-evaluation for teachers and focus on the individualized supervision, the establishment of expert evaluation team, feedback regulation, and the observation in the classroom which is of great importance [77]. Changes in guiding practice to independent practice through regular rating and occasional evaluation improves teachers' teaching skills and evaluation skills.

\section{Disclosure}

W. Jiayi is the provincial superintendent of Education in Gansu, China, a Professor at Northwest Normal University's Research Center for the Development of Northwest Minority Education, and Vice President of the Chinese Society of Education. C. Ling is a P.H.D degree student at Northwest Normal University's Research Center for the Development of Northwest Minority Education.

\section{References}

[1] B. Wang, "Teacher evaluation model: contract plan method," Forum on Contemporary Education, vol. 5, pp. 5-8, 2003.

[2] B. Wang, "Teacher evaluation model: teaching portfolio," Theory and Practice of Education, vol. 7, pp. 24-28, 2004.

[3] B. Wang, "Teacher evaluation model:the microteaching evaluation method," Global Education, vol. 9, pp. 43-47, 2004.

[4] B. Wang, "Teacher evaluation: a review of the elimination system," Global Education, vol. 12, pp. 62-66, 2004.

[5] B. Wang, "Teacher evaluation: performance evaluation method," Global Education, vol. 5, pp. 47-51, 2005.

[6] B. Wang, "Teacher evaluation: value-added assessment method," Theory and Practice of Education, vol. 12, pp. 20-23, 2005.

[7] Y. Cai and H. Tianyuan, "The origin, problem and its development trend of teacher evaluation study," Journal of Beijing Normal University, vol. 1, pp. 130-136, 2003.

[8] Y. Cai, "Review and reflection on teacher performance assessment studies," Teacher Education Research, vol. 5, pp. 73-76, 2001.

[9] Y. Cai and C. Lin, "Theory and practice of teacher performance evaluation," Teacher Education Research, vol. 1, pp. 3641, 2005.
[10] Y. Cai, L. Chongde, and C. Xuefeng, "Confirmatory factor analysis of students' evaluations on teacher performance," Acta Psychologica Sinica, vol. 35, no. 3, pp. 362-369, 2003.

[11] Y. Liu, "The theories and models of developing teacher evaluation," Theory and Practice of Education, vol. 12, pp. 2832, 2001.

[12] X. Zhao, "The development trend of the overseas development of teacher evaluation," Comparative Education Research, vol. 1, pp. 72-75, 2003.

[13] L. Wu et al., "Developing teacher evaluation exploration," Exploring Education Development, vol. 4-5, pp. 169-172, 2003.

[14] Q. Li, "The development teacher evaluation and teacher growth," Education Review, vol. 3, pp. 44-46, 2002.

[15] Q. Li, "The comparative of two teacher evaluation systems research," Journal of Teaching and Management, vol. 8, pp. 23$25,2002$.

[16] B. Wang, The System of Appraisal for Development, East China Normal University Press, Shanghai, China, 1998.

[17] Y. Zhao, "Traditional teacher evaluation and development of teachers evaluation comparative study," Liaoning Education Research, vol. 10, pp. 45-46, 2001.

[18] Y. Liu and Z. Weixin, "A study of developing teacher evaluation," Journal of the Chinese Society of Education, vol. 10, pp. 55-56, 2002.

[19] W. Chen, "Play the incentive function of development teacher evaluation," Theory and Practice of Education, vol. 10, pp. 17$18,2003$.

[20] B. Chen and X. Bingou, "Build development teacher evaluation system-teacher professionalism perspective," Theory and Practice of Education, vol. 5, pp. 50-53, 2006.

[21] B. Wang, "The comparison of rewards and punishments and developing teacher evaluation system," Shanghai Research on Education, vol. 12, pp. 39-41, 2007.

[22] J. Yang and W. Zhuo, "On the relationship between the development evaluation and reward and punishment evaluation of teachers," Journal of the Chinese Society of Education, vol. 1, pp. 46-48, 2003.

[23] J. Yang and W. Zhuo, "On the essence of China's development of teacher evaluation," Education Science, vol. 2, pp. 14-16, 2005.

[24] Q. Zhang, "Examination and Consideration of developing teacher evaluation-a dialogue with Professor Wang Binhua," Educational Research and Experiment, vol. 1, pp. 61-64, 2005.

[25] Q. Zhang, "Review of one conclusion of the system of appraisal for development-a dialogue with Professor Wang Binhua," Comparative Education Research, vol. 4, pp. 86-90, 2005.

[26] R. Li, "Composite evaluation: a rational choice of the teacher evaluation," School Management, vol. 3, pp. 16-18, 2003.

[27] W. Guo and D. Zhiming, "Exploration and research of the domestic teacher evaluation system," Theory and Practice of Education, vol. 9, pp. 39-41, 2007.

[28] X. Zhu, Jiangchengxing Jiaoshi Pingjia he Fazhanxing Jiaoshi Pingjia de Zhenghe Yanjiu, Shandong Normal University, Jinan, China, 2005.

[29] X. Zeng, "Combing of primary and secondary teacher performance evaluation process," Teacher Education Research, vol. 1, pp. 47-51, 2004.

[30] L. Duan and Y. Limin, "On the, "people-oriented" teacher performance evaluation," University Education Science, vol. 4, pp. 64-67, 2003.

[31] F. Hu, "Aphasia and noise-the discourse phenomena in teacher evaluation practice," Theory and Practice of Education, vol. 12 , pp. 30-34, 2002. 
[32] C. Hou, "Teachers' reflective self-evaluation," Theory and Practice of Education, vol. 4, pp. 27-32, 2003.

[33] Y. Xu, "On the "good teacher"-"teacher evaluation" evaluation," Curriculum, Teaching Material and Method, vol. 11, pp. 45-51, 1997.

[34] J. Yu, "The positioning and the basis of the teacher evaluation reform," Curriculum, Teaching Material and Method, vol. 9, pp. 67-70, 2001.

[35] X. Zhang, "Three basic questions of the current teacher evaluation critique: postmodern perspective," Theory and Practice of Education, vol. 10, pp. 32-35, 2004.

[36] B. Wang, "An analysis of teacher evaluation methods and main application," Teacher Education Research, vol. 1, pp. 42-50, 2005.

[37] X. Liu, "On the construction and operating strategy of the teachers' development evaluation model," Journal of Education Development, vol. 12, pp. 42-44, 2004.

[38] J. Wang, "Professional development of teachers and teachers' self-evaluation," Teacher Education Research, vol. 3, pp. 26-31, 2002.

[39] X. Wang, "The new progress of the teacher evaluation system in the United Kingdom -and PRP system plan commentary," Comparative Education Research, vol. 3, pp. 43-47, 2002.

[40] P. Ying and F. Guorui, "A case studies on teacher evaluation model," Theory and Practice of Education, vol. 3, pp. 22-25, 2001.

[41] B. Ou and L. Junju, "An analysis of the main in diverse teachers evaluation," Journal of Chongqing University, vol. 2, article 129, 2004.

[42] J. Li, "Study the combination of self-evaluation and othersevaluation in the education evaluation activities," Education Review, vol. 1, pp. 36-38, 1999.

[43] B. Wang, "Teacher evaluation criteria research," Teachers Education Research, vol. 11, pp. 53-57, 2009.

[44] J. Zhang, "Teacher evaluation and academic moral construction," China University Teaching, vol. 9, pp. 8-9, 2002.

[45] H. Yang, "Problems and solution strategies of China's teacher evaluation methods," Journal of Liaoning Normal University, vol. 9, pp. 55-56, 2001.

[46] J. Shen, "A lot of problems in the teacher evaluation system need to urgent reconstruction," China Education Daily, vol. 14, article 6, 2009.

[47] Y. Tu, "British teacher evaluation summary," Studies in Foreign Education, vol. 5, pp. 54-57, 1993.

[48] B. Wang, "Teacher evaluation system-the major initiatives of the British educational reform," Foreign Education Data, vol. 1, pp. 28-34, 1995.

[49] F. Mu, "Teacher evaluation system in British," School Management, vol. 4, pp. 44-45, 1998.

[50] A. Tang et al., "The impact analysis of British PRP teacher evaluation system for teachers' professional development," Global Education, vol. 10, article 80, 2005.

[51] K. Wang and Z. Wenhua, "Yingguo jichu jiaoyu jiaoshi pingjia zhidu gaige pingjian," Studies in Foreign Education, vol. 12, pp. 68-72, 2006.

[52] M. Xu, "Evaluation system and the characteristics of the British primary and secondary school teachers," Studies Foreign Education, vol. 12, pp. 45-49, 2002.

[53] B. Cai and C. Yanwei, "The new system of British teachers' classroom teaching evaluation: concepts, standards and the effect of implementation," Global Education, vol. 1, pp. 67-71, 2008.

[54] W. Che, The Experience and Enlightenment of Performance Management Teacher Evaluation System in British Primary and Middle Schools, Northwest Normal University, Lanzhou, China, 2009.

[55] B. Sun and S. Jiliang, "The history and models of teacher evaluation in US," Comparative Education Review, vol. 5, pp. 73-76, 2009.

[56] Q. Zhan, "The comparative of teacher evaluation system in UK and US," Elementary and Schooling Abroad, vol. 1, pp. 18-20, 1998.

[57] Y. Wang, "Test method in the U.S. teacher evaluation," Foreign Education News, vol. 3, pp. 42-43, 1990.

[58] A. Tian, "Evaluation system of the United States based on the teachers' behavior," Studies in Foreign Education, vol. 4, pp. 15$18,2003$.

[59] X. Lu and B. Wuyun, "The reform and development trend of the teacher evaluation system in America," Education Research, vol. 10, article 93, 2002.

[60] C. Xiang, "The course of development of the latest reform movements of the teacher evaluation," Studies in Foreign Education, vol. 9, pp. 63-65, 2006.

[61] R. Miao and Z. Xiaolei, "From teacher education technology capability assessment to senior teacher certification," China Educational Technology, vol. 10, pp. 11-15, 2010.

[62] Y. Xiao and G. Jun, "Contemporary American exploration of teacher evaluation criteria," Education Exploration, vol. 3, pp. 142-143, 2008.

[63] W. Wang, "Reform of teacher evaluation in the context of the performance system and its implications," Elementary and Secondary Schooling Abroad, vol. 10, pp. 27-31, 2011.

[64] W. Pang, The Research on American Value-Added Assessment of Teachers in the Elementary and Secondary Schools, vol. 4, Southwest University, Chongqing, China, 2009.

[65] D. Hou, L. Gu, and Z. Wang, "The new trends of the reform of teacher evaluation in America," Global Education, vol. 10, pp. 72-75, 2005.

[66] M. Cai, "The useful experience of the teachers evaluation reform in American primary and secondary schools," Journal of the Chinese Society of Education, vol. 7, pp. 65-68, 2007.

[67] C. Zhou and J. Yongtao, "The three themes of the teacher evaluation study in American," Studies Foreign Education, vol. 1, pp. 1-6, 2007.

[68] M. Luo, "Teacher evaluation and school effectiveness research in America," Heilongjiang Researchs on High Education, vol. 3, pp. 65-68, 2010.

[69] H. Sun, Z. Dan, and G. Hui, "Comparison and enlightenment of the evaluation index system of teacher of China and America," Exploring Education Development, vol. 20, pp. 5458, 2008.

[70] N. Yang, American Differentiated Teacher Evaluation SystemExperience and Enligntenment, Capital Normal University, Beijing, China, 2007.

[71] S. Li and C. Min, "American skilled teachers performance evaluation and its implications," Studies in Foreign Education, vol. 11, pp. 81-84, 2008.

[72] S. Liu and L. Xingfa, "An exploration of teaching evaluation method in the new curriculum concept-review of the United States teaching portfolio," Studies in Foreign Education, vol. 5, pp. 30-34, 2002.

[73] S. Yin and C. Fu, "American teachers teaching portfolio assessment on the revelation of our kindergarten teacher evaluation," Studies in Preschool Education, vol. 9, pp. 50-53, 2008.

[74] H. Ma, "Teaching portfolio development-a new path for teachers' professional development and evaluation," Theory and Practice of Education, vol. 1, pp. 11-16, 2010. 
[75] A. Xie and L. Xiao, "Electronic portfolio in teacher evaluation," Global Education, vol. 11, pp. 76-80, 2005.

[76] H. Ma, "Review of the U.S. teaching portfolio assessment," Comparative Education Review, vol. 1, pp. 78-82, 2004.

[77] S. Xu and H. Qingxiang, "The inspiration to improve the quality of adult education about the American teacher evaluation system," China Adult Education, vol. 2, pp. 124126, 2007. 


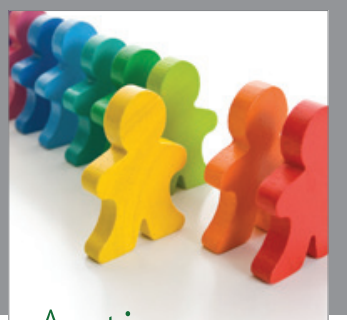

Autism

Research and Treatment
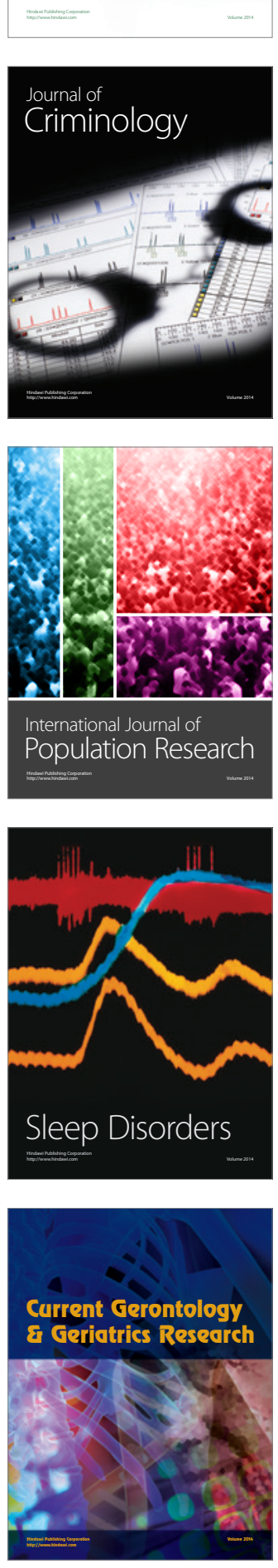
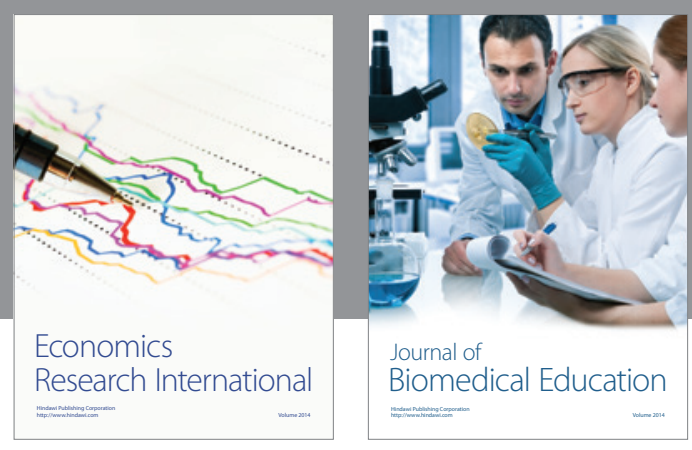

Journal of

Biomedical Education

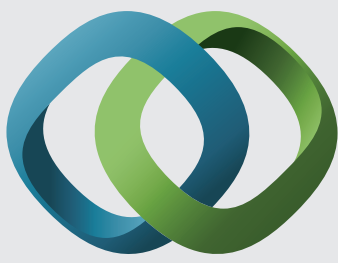

\section{Hindawi}

Submit your manuscripts at

http://www.hindawi.com
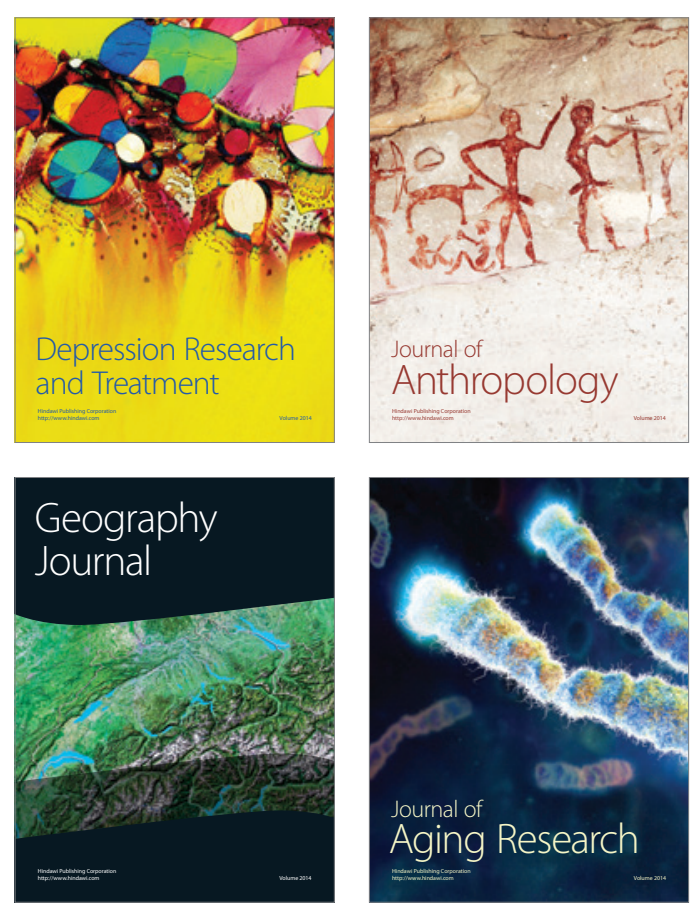

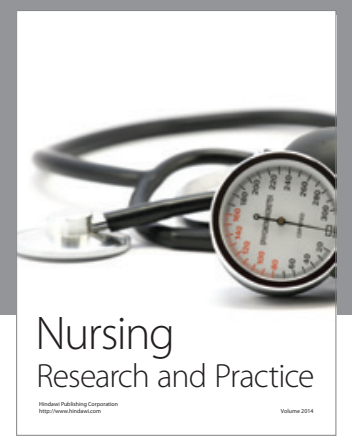

Nursing

Research and Practice

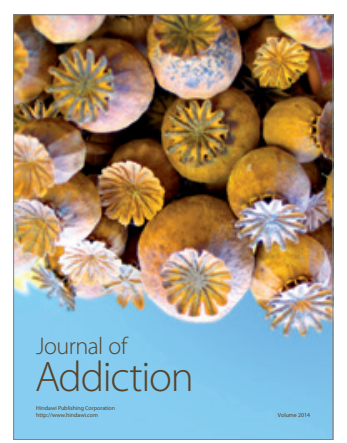

Child Development

Research

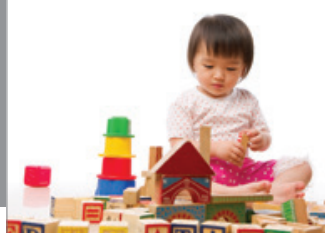

迥
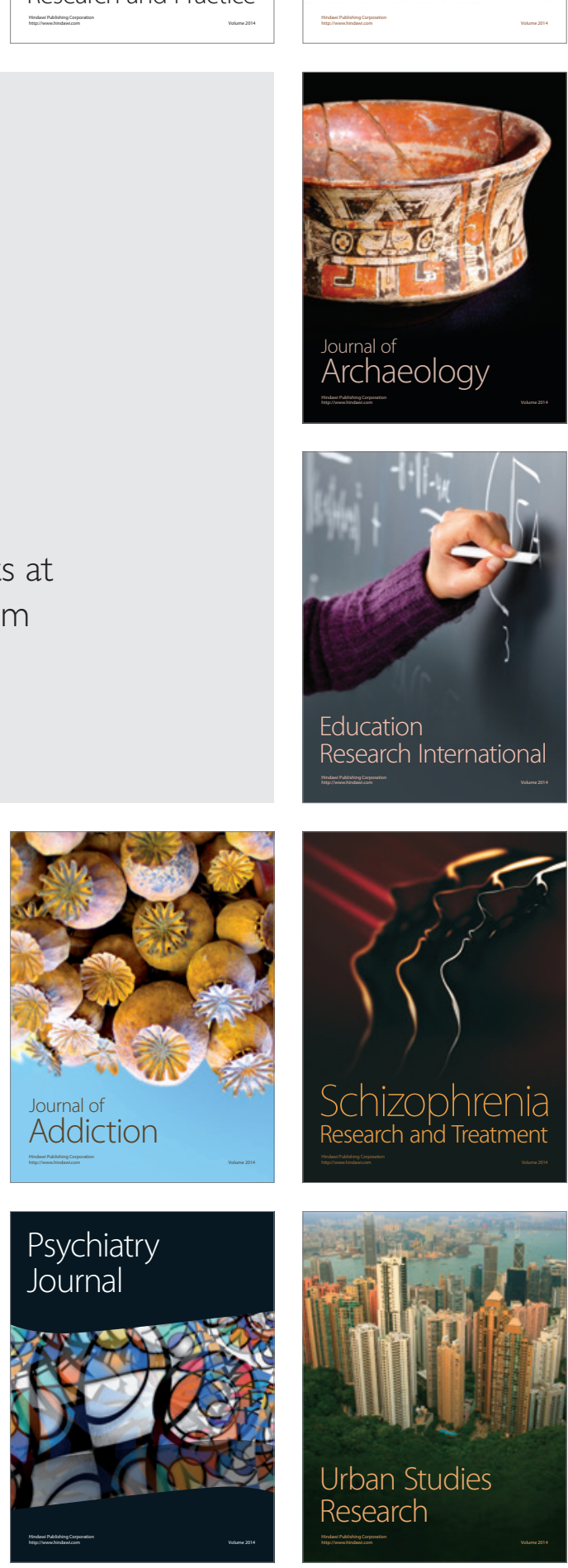